\title{
Efficacy and safety of botulinum toxin a injection into urethral sphincter for underactive bladder
}

\author{
Guoqing Chen ${ }^{1,2}$, Limin Liao ${ }^{1,2^{*}}$ (D) and Fei Zhang ${ }^{3}$
}

\begin{abstract}
Background: The aim of this retrospective study was to evaluate the clinical efficacy and safety of botulinum toxin type $A(B T X-A)$ injection into the urethral sphincter to treat patients with underactive bladder (UAB).

Methods: From September 2012 to December 2018, 35 patients with UAB who presented with dysuria were treated with BTX-A (Prosigne ${ }^{\varpi}$, Lanzhou Biological Products, Lanzhou, China). All patients were evaluated using the International Continence Society standard for video-urodynamic examination before and 1 month after treatment. The index includes maximum urinary flow rate, detrusor leak point pressure, and maximum urethral pressure. Post-voiding residual urine volume was measured using ultrasound before, one and 3 months post injection.

Results: After 1 month of treatment, the maximum flow rate increased from $2.5 \pm 1.1 \mathrm{ml} / \mathrm{s}$ to $6.6 \pm 1.7 \mathrm{ml} / \mathrm{s}(P<0.05)$. The maximum urethral pressure decreased from $73.5 \pm 5.8 \mathrm{cmH}_{2} \mathrm{O}$ to $45.6 \pm 4.3 \mathrm{cmH}_{2} \mathrm{O}(P<0.05)$. The detrusor leak point pressure decreased from $69.9 \pm 20.7 \mathrm{cmH}_{2} \mathrm{O}$ to $26.3 \pm 7.4 \mathrm{cmH}_{2} \mathrm{O}(P<0$. 01). Post-voiding residual urine decreased from $282.8 \pm 134.2 \mathrm{ml}$ to $125.0 \pm 92.1 \mathrm{ml}(P<0.01)$ but increased to $270.1 \pm 129.0 \mathrm{ml} 3$ months post injection. Of the 35 patients, 57.1\% (20/35) relied on clean intermittent catheterization (CIC) before injection, but 75.0\% (15/20) of them could partly void 1 month after injection, and 25\%(5/20) could void without CIC. Eight patients showed hydronephrosis before treatment; in three of them, hydronephrosis decreased slightly, while it resolved in two. All patients were followed for three to 6 months, and the effect lasted for about two to 3 months. No serious adverse events occurred in any patient.
\end{abstract}

Conclusions: The results suggest that Prosigne ${ }^{\varpi}$ injection into the urethral sphincter is an effective, safe, and inexpensive way to treat UAB.

Keywords: Urethral sphincter, Botulinum toxin type A, Underactive bladder, Residual urine volume

\section{Background}

Botulinum toxins (BTX) which derive from the Grampositive coccus Clostridium botulinum are the most potent known naturally occurring neurotoxins [1]. They can paralyze striated muscle by blocking acetylcholine release at the presynapse. U.S. Food and Drug Administration approved BTX for the treatment of strabismus, blepharospasm, and hemifacial spasm in 1989 [2]. BTX can be classified into seven different types: A, B, C, D, E, $\mathrm{F}$, and $\mathrm{G}$ according to its different immune antigens [3]. The first licensed serotype in clinical use was BTX-A

\footnotetext{
* Correspondence: Imliao@263.net

${ }^{1}$ Department of Urology, China Rehabilitation Research Center, Beijing 100068, China

2Department of Urology, Capital Medical University, Beijing, China Full list of author information is available at the end of the article
}

with the trade name Botox (Allergan Pharmaceuticals, Irvine, CA), but other brands also exist, including Dysport ${ }^{\circ}$ (Ipsen Biopharm Ltd., Slough, UK), Xeomin ${ }^{\circ}$ (Merz Pharmaceuticals UK Ltd., Hertfordshire, UK), Prosigne (Lanzhou Biological Products, Lanzhou, China), and PurTox $^{\bullet}$ (Mentor Corporation, Madison, WI) [4].

In recent years, BTX-A injection has been widely used in the treatment and research of lower urinary tract dysfunction [5]. The site of BTX-A injection is classified into simple detrusor injection for detrusor overactivity, simple sphincter injection, or detrusor-sphincter combined injection for sphincter spasm or detrusor sphincter dysfunction. Our department is the first in China to use BTX-A injection to treat lower urinary tract dysfunction. We used BTX-A (Prosigne ${ }^{\circ}$ ) injected into the

(c) The Author(s). 2019 Open Access This article is distributed under the terms of the Creative Commons Attribution 4.0 International License (http://creativecommons.org/licenses/by/4.0/), which permits unrestricted use, distribution, and 
detrusor for neurogenic detrusor overactivity [6] and interstitial cystitis [7] and achieved satisfactory results. We also used Prosigne ${ }^{\bullet}$ to inject into the urethral sphincter to treat underactive bladder (UAB). This retrospective study was to evaluate the efficacy and safety of Prosigne ${ }^{\bullet}$ in patients with $\mathrm{UAB}$.

\section{Methods}

All subjects signed their informed consent for inclusion before they participated in the study. The study was conducted in accordance with the Declaration of Helsinki, and the protocol was approved by the Ethics Committee of China Rehabilitation Research Center (Project identification code: 2018-053-1). Before treatment, all patients underwent video-urodynamic examination according to the International Continence Society standard [8], and the maximum urinary flow rate, maximum urethral pressure, and detrusor leak point pressure were recorded. According to the classification of urodynamic diagnosis, 26 patients had detrusor underactivity, and nine had acontractile detrusor. There was no bladder-ureter reflux, and urinary ultrasound showed that eight patients had mild hydronephrosis. Twenty of the 35 patients had previously relied on clean intermittent catheterization (CIC). The above indicators were reviewed 1 month after treatment. Residual urine volume was measured by ultrasound before, one and 3 months post injection, and the mean of three measurements was taken.

BTX-A (Prosigne ${ }^{\circ}$ ) was used in treatment. The patients were treated in the lithotomy position with routine insertion of a $21 \mathrm{~F}$ cystourethroscope. After identifying the circular external sphincter under the endoscope, a $6 \mathrm{~F}$ bladder injection needle was inserted into the external sphincter using cystourethroscopy. One-hundred units of BTX-A were diluted with $8 \mathrm{ml} \mathrm{sa-}$ line and injected into the external sphincter. In the direction of the $3,6,9$, and 12 points of the external sphincter, two needles were injected longitudinally near each point, a total of 8 needles. Each injection was $1 \mathrm{ml}$ and 1 or $2 \mathrm{~cm}$ deep at the latent injection site. And after the operation, Foley catheter was indwelled.

Using GraphPad Prism 8 software, all measurement data were expressed by mean \pm standard deviation; the paired $t$ test and one-way ANŌVA was used for group measurement data. $P<0.05$ was considered to be statistically significant.

\section{Results}

From September 2012 to December 2018, 35 patients with $\mathrm{UAB}$ and dysuria underwent BTX-A (Prosigne ${ }^{\circ}$ ) injection into their urethral sphincter in our hospital, including 21 men and 14 women aged 19 to $77(41.85 \pm 15.80)$ years. Twenty-four patients had neurogenic bladder, and 11 had non-neurogenic, non-obstructive urinary retention. Specific etiologies are shown in Table 1. All patients were given a thorough explanation of the treatment and written informed consent before the injection.

The catheter was removed 7 days after injection with BTX-A. One month after treatment, all patients underwent video-urodynamic examination. The maximum urinary flow rate increased $(P<0.05)$, while the maximum urethral pressure and detrusor leak point pressure reduced by statistically significant amounts $(P<0.05)$ (Table 2). Residual urine decreased significantly 1 month post injection $(P<0.05)$ but increased to the same level as before treatment 3 months post injection (Fig. 1). Of the 35 patients, $57.1 \%(20 / 35)$ relied on CIC before injection, but $75.0 \%(15 / 20)$ of them could partly void 1 month after injection, and 25\% (5/20) could void without CIC.

Urinary ultrasonography was conducted 1 month after treatment. Three patients had hydronephrosis without obvious relief, three had slight relief from hydronephrosis, and two had resolution of their hydronephrosis. The follow-up period was three to 6 months, and the relief lasted two to 3 months. No serious adverse reactions occurred in any patient. None of the patients had incontinence before the procedure, but mild urinary stress incontinence occurred in five patients after treatment and resolved two or 3 months later.

\section{Discussion}

UAB is a complicated clinical syndrome characterized by prolonged urination, with or without a sensation of incomplete bladder emptying, usually with hesitancy, a slow stream, and reduced sensation on filling [9]. According to possible mechanisms, UAB can be classified into three types: idiopathic, neurogenic, or myogenic [10]. In our study, 24 patients had neurogenic bladder, and 11 had non-neurogenic, non-obstructive urinary retention. Based on urodynamic examination, UAB can be classified into detrusor underactivity or acontractile detrusor [10]. In this study, 26 patients had detrusor underactivity, and nine had contractile detrusor.

Whether UAB was neurogenic or nonneurogenic, the main symptom of all patients was dysuria, which negatively affects quality of life-especially in patients with hydronephrosis due to ureteral reflux, in whom renal

Table 1 Patient's etiologies

\begin{tabular}{ll}
\hline Etiology & $\begin{array}{l}\text { Number of } \\
\text { patients }\end{array}$ \\
\hline Neurogenic decease & 24 \\
Cone horsetail injury & 10 \\
Spina bifida and meningocele & 8 \\
Spinal surgery & 6 \\
Non-neurogenic, non-obstructive urinary retention & 11 \\
Total & 35 \\
\hline
\end{tabular}


Table 2 Comparison of urodynamic parameters in patients with underactive bladder before and after treatment

\begin{tabular}{lll}
\hline Urodynamic parameters & Baseline & One month \\
\hline Pura.max $\left(\mathrm{cmH}_{2} \mathrm{O}\right)$ & $773.5 \pm 5.8$ & $45.6 \pm 4.3^{*}$ \\
DLPP $\left(\mathrm{cmH}_{2} \mathrm{O}\right)$ & $769.9 \pm 20.7$ & $26.3 \pm 7.4^{*}$ \\
Qmax $(\mathrm{ml} / \mathrm{s})$ & $2.2 .5 \pm 1.1$ & $6.6 \pm 1.7^{*}$
\end{tabular}

DLPP Detrusor leak point pressure, Pura.max Maximum urethral pressure, Qmax Maximum urinary flow rate. *: $p<0.05$

dysfunction may occur at any time and be life-threatening. Reducing residual urine, avoiding overdistension, and preventing upper urinary tract damage are considered appropriate management for patients with UAB [9].

For these patients, the gold standard of treatment is intermittent catheterization [10]. However, some young patients do not accept intermittent catheterization but try to excrete urine through manual-assisted urination. Because manual-assisted urination (Crede and Valsalva urination) may cause bladder pressure to exceed the safe range, this method could induce or aggravate upper urinary tract damage and is not recommended [11]. For some patients in stable condition with no upper urinary tract damage and a strong willingness to urinate autonomously, BTX-A injection into the urethral sphincter combined with autonomous urination can be considered. However, long-term follow-up is necessary during the application period.

BTX-A is a pathogenic substance and the most powerful natural neurotoxin in nature. This neurotoxin infiltrates the nerve endings of presynaptic cholinergic neurons, enters neurons through receptor-mediated endocytosis, and catalyzes the decomposition of SNAP25 protein, promoting the fusion of synaptic vesicles. This cleavage inhibits the secretion of acetylcholine, resulting in temporary chemical denervation and loss or weakening of nerve activity in target organs [3]. Usually, the chemical denervation is reversible. Dykstra et al. first injected 100 units of BTX-A into the external urethral sphincter to treat patients with spinal cord injury in 1988 [12]. They concluded that the pressure of the urethra and bladder was reduced at the same time.

In this study, 35 patients with UAB underwent BTX-A injection into the urethral sphincter in our hospital. After treatment, the maximum urinary flow rate increased, while residual urine, maximum urethral pressure, and detrusor leak point pressure decreased.

The decrease of maximum urethral pressure and DLPP can effectively alleviate the effect of high bladder pressure on upper urinary tract. In this study, of eight patients with mild hydronephrosis before treatment, three had slight relief and two had resolution 1 month after injection. Fifteen patients still did not completely detach from CIC, but they can partially urinate autonomously and the frequency of CIC was reduced which improved the quality of life.

Although urethral BTX-A injection may increase the risk of urinary incontinence, this side effect gradually decreases as the BTX-A action is lost. The effect of BTX-A on the external urethral sphincter lasts for only three to 4 months, so patients require repeated injections; this negatively affects patient adherence. In this study, we used BTX-A (Prosigne ${ }^{\circ}$ ) to treat UAB. In clinical terms, Prosigne $^{\circ}$ can achieve satisfactory results in patients with detrusor overactivity, interstitial cystitis, or UAB. It is also inexpensive.

Unfortunately, the limitation of this study is that the sample size was small and heterogeneous. It is not clear how effective the BTX-A was in the subgroup of patients with neurogenic diseases. In the future, we need to increase the sample size to further clarify which subgroup BTX-A was better for.

\section{Conclusions}

Prosigne ${ }^{\circ}$ urethral sphincter injection is a highly effective, minimally invasive, and inexpensive method for the treatment of UAB.

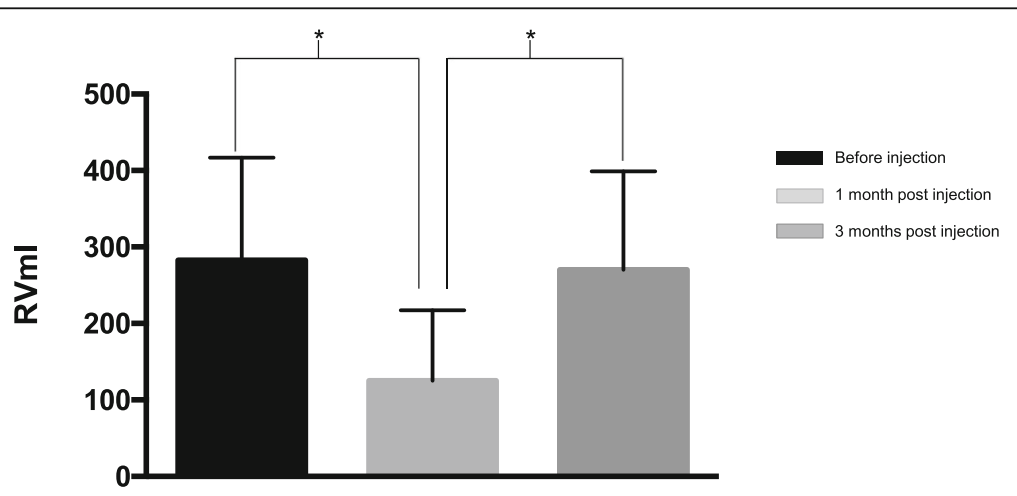

Fig. 1 Residual urine volume before, one and three months post injection. *: $P<0.05$ 


\section{Abbreviations}

BTX-A: Botulinum toxin type A; DLPP: Detrusor leak point pressure; Pura.max: Maximum urethral pressure; Qmax: Maximum urinary flow rate; UAB: Underactive bladder

\section{Acknowledgements}

Not applicable.

\section{Authors' contributions}

GC participated in all procedures. He was responsible for data gathering and writing papers. FZ was responsible for data gathering and analyzing. LL was responsible for drafting and guiding work, as well as modifications to the thesis. All authors read and approved the final manuscript.

\section{Funding}

This study was funded by China Rehabilitation Research Center foundation (No.2018zx-14). Data collection, analysis and publication charges are funded by the project. The funder of the project conceived and designed the work.

\section{Availability of data and materials}

The datasets used and/or analyzed during the current study are available from the corresponding author on reasonable request.

\section{Ethics approval and consent to participate}

All subjects signed their informed consent for inclusion before they participated in the study. The study was conducted in accordance with the Declaration of Helsinki, and the protocol was approved by the Ethics Committee of the China Rehabilitation Research Center (Project identification code: 2018-053-1).

\section{Consent for publication}

Not applicable.

\section{Competing interests}

The authors declare that they have no competing interests.

\section{Author details}

${ }^{1}$ Department of Urology, China Rehabilitation Research Center, Beijing 100068, China. ${ }^{2}$ Department of Urology, Capital Medical University, Beijing, China. ${ }^{3}$ Department of Urology, Baotou Central Hospital, Baotou 014040,

China.

Received: 2 February 2019 Accepted: 26 June 2019

Published online: 05 July 2019

\section{References}

1. Rasetti-Escargueil C, Lemichez E, Popoff MR. Variability of botulinum toxins: challenges and opportunities for the future. Toxins (Basel). 2018;10:374-87.

2. Jankovic J. Botulinum toxin: state of the art. Mov Disord. 2017:32:1131-8.

3. Domenico T, Marco P. Novel botulinum neurotoxins: exploring underneath the iceberg tip. Toxins (Basel). 2018;10:190-207.

4. Gulamhusein A, Mangera A. OnabotulinumtoxinA in the treatment of neurogenic bladder. Biologics. 2012;6:299-306.

5. Jhang JF, Kuo HC. Botulinum Toxin A and lower urinary tract dysfunction: pathophysiology and mechanisms of action. Toxins (Basel). 2016;8:120-31.

6. Chen $\mathrm{G}$, Liao L. Injections of Botulinum Toxin A into the detrusor to treat neurogenic detrusor overactivity secondary to spinal cord injury. Int Urol Nephrol. 2011;43:655-62.

7. Gao Y, Liao L. Intravesical injection of botulinum toxin A for treatment of interstitial cystitis/bladder pain syndrome: 10 years of experience at a single center in China. Int Urogynecol J. 2015;26:1021-6.

8. Rosier PFWM, Schaefer W, Lose G, Goldman HB, Guralnick M, Eustice S, et al. International Continence Society Good Urodynamic Practices and Terms 2016: Urodynamics, uroflowmetry, cystometry, and pressure-flow study. Neurourol Urodyn. 2017;36:1243-60

9. Li $X$, Liao L. Updates of underactive bladder: a review of the recent literature. Int Urol Nephrol. 2016:48:919-30.

10. Li X, Liao L, Chen G, Wang ZX, Lu TJ, Deng H. Clinical and urodynamic characteristics of underactive bladder: Data analysis of 1726 cases from a single center. Medicine. 2018;97:9610-3.

11. Chang YH, Siu JJ, Hsiao PJ, Chang CH, Chou EC. Review of underactivebladder. J Formos Med Assoc. 2018;117:178-84.
12. Dykstra DD, Sidi AA, Scott AB, Pagel JM, Goldish GD. Effects of botulinum A toxin on detrusor-sphincter dyssynergia in spinal cord injury patients. J Urol. 1988;139:919-22.

\section{Publisher's Note}

Springer Nature remains neutral with regard to jurisdictional claims in published maps and institutional affiliations.
Ready to submit your research? Choose BMC and benefit from:

- fast, convenient online submission

- thorough peer review by experienced researchers in your field

- rapid publication on acceptance

- support for research data, including large and complex data types

- gold Open Access which fosters wider collaboration and increased citations

- maximum visibility for your research: over $100 \mathrm{M}$ website views per year

At $\mathrm{BMC}$, research is always in progress.

Learn more biomedcentral.com/submissions 